\title{
A green approach toward epoxy-benzoxazine copolymers with shape-memory ability
}

\author{
R. Ambrožič, A. Ručigaj, M. Krajnc* \\ University of Ljubljana, Faculty of Chemistry and Chemical Technology, Večna pot 113, 1000 Ljubljana, Slovenia
}

Received 19 November 2019; accepted in revised form 21 January 2020

\begin{abstract}
In the frame of green-based chemistry, advanced shape memory polymers are designed from benzoxazine (RS$\mathrm{BOX}$ ) and epoxy (R-EP) resins basing on potential natural raw materials, such as resorcinol and stearylamine. Thermal curing, investigated by differential scanning calorimetry, shows several overlapping peaks suggesting a complex curing mechanism. Dynamic mechanical analysis of cured RS-BOX/R-EP copolymers demonstrates an increase in the glass temperature and narrower glass transition by the increase of the RS-BOX ratio. In contrast, crosslinking density increases with higher epoxy resin content. All investigated materials possess one-way dual shape memory ability triggered by glass transition temperature with excellent shape fixity, while the shape recovery values ranged between 95 and $100 \%$. The duration of the recovery process is significantly influenced by the RS-BOX amount. Additionally, the mechanical and shape memory properties of fully bio-based SMPs might be suitably tailored for advanced applications by merely varying the initial composition.
\end{abstract}

Keywords: smart polymers, shape memory materials, bio-benzoxazine, epoxy

\section{Introduction}

Shape memory polymers (SMPs) represent a novel class of polymer materials with the ability to recover their original shape upon external stimuli, such as heat, light, electric field, and $\mathrm{pH}[1,2]$. Among these, heat is most commonly applied to trigger shape memory by glass transition temperature $\left(T_{\mathrm{g}}\right)$ or melting temperature $\left(T_{\mathrm{m}}\right)$ approach [3]. SMPs materials are becoming intensively investigated due to the great commercial applicability including the high-tech industries, such as aerospace, electronics, medication and construction [4]. However, achieving full shape memory recovery over the wide range of temperatures remains a significant challenge. Following sustainable development, much attention is also given to the development of bio-based smart materials [5]. Recently, SMP bio-based epoxy was applied as a shape memory polymer composite leading to sustainable development and environmental acceptability [6-8].
The SMPs can be either thermoplastics, e.g. polyester, polyethylene, and polypropylene [9-11], or thermosets such as epoxy $[12,13]$ or polybenzoxazine [14]. The network of thermoplastics can be constructed with physical crosslinks, which make the reshaping or re-formation of polymers simpler; however, the potential melting at higher temperatures could present a critical applicative issue. On the other hand, thermosets possess chemical crosslinks, and at elevated temperatures (higher than $T_{\mathrm{g}}$ ) become softer, and yet do not melt [15]. Consequently, thermosets are highly attractive and widely used as SMP materials, especially epoxy-based materials which were developed for several advanced applications $[2,13]$. Even more, the property range could be furtherly broadened by developing copolymers and composites in order to tailor $T_{\mathrm{g}}[16]$.

Benzoxazine resin is a relatively new class of phenolic resins which, besides the flexibility of the benzoxazine 
monomer molecule design, possesses exceptional thermal stability, suitable mechanical and electrical properties, high glass transition temperature, low water absorption and low viscosity melt. Moreover, the ability of benzoxazine resin to blend with other polymers gives this material an even broader range of applications. The resin can act as a curing agent for epoxy resulting in a copolymer network [17]. The broad molecular design flexibility makes benzoxazines an excellent tool to prepare materials with target application properties [18, 19]. Recently, polybenzoxazine-epoxy SMPs were developed possessing the quality of both resulting in the common effect in the thermal and mechanical properties of benzoxazine/epoxy copolymer [20].

Rimdusit et al. [20] prepared benzoxazine-modified epoxy resin that consisted of aromatic and aliphatic epoxy and bisphenol A-aniline based benzoxazine (BA-a), which was added into the prepared mixture to control the shape recovery time. All prepared samples showed high shape recovery and shape fixity ratios. Additionally, due to the increased mole ratio of BA-a, the recovery stress values increased. In further research, Tanpitaksit et al. [21] used BA-a and aliphatic epoxy and achieved a similar trend as previously observed with improved thermal and mechanical properties. In one of the latest researches, Likitaporn et al. [22] achieved outstanding recovery stress improvement by reinforcing the benzoxazine-epoxy polymers with adamantine silicon carbide whisker up to $20 \mathrm{wt} \%$. Liu et al. [23] prepared several polybenzoxazines based on polyetheramine which exhibited one-way dual-shape memory behavior. The study focused on the effects of different benzoxazine functionalization (ortho-, para- and meta- positions) on the mechanical and shape memory effects [24]. Further on, shape memory polymers were prepared from BA-a resin and urethane prepolymer by Prathumrat et al. [25], also achieving high shape recovery and shape fixity (up to 99\%). Several studies showed exceptional mechanical and shape memory possibilities; however, the improvements could be implemented, particularly in the field of bio-based SMP.

Recently, the replacement of the petroleum-derived materials by bio-based and bio-compatible polymeric materials has been a key subject of interest to academia and industry [26-30]. In this context, the purpose of our study was to explore the possibility of developing a fully bio-based polybenzoxazine-epoxy material possessing satisfactory shape memory ability.
In several studies, resorcinol [26], stearylamine [28], and paraformaldehyde $[26,28]$ were introduced as potential natural feedstocks for benzoxazine and epoxy monomers synthesis. Resorcinol is naturally available phenol, produced from biomass through fermentative and/or chemical processes. Its structure enables the formation of bis-functional monomers (epoxy and benzoxazine), allowing greater flexibility of the final material essential for SMP applications. Besides, stearylamine can be prepared from vegetable oils, while the bio-methanol can be converted into formaldehyde via catalytic oxidation, and further to paraformaldehyde by a condensation reaction. Nevertheless, it is important to emphasize that although the methods for the synthesis of listed materials from natural sources are described, the employed chemicals used for synthesis were purchased from synthetic sources alone. Yet, once these compounds will be commercially available from natural sources, one can utilize it for the synthesis of entirely natural benzoxazine-epoxy copolymers. To define applied assets of resulting materials, shape memory ability was investigated, stimulated by heat and triggered by a $T_{\mathrm{g}}$. Structure/performance relationship was investigated to gain deeper insight into the applicability and feasibility of prepared SMP materials. Accordingly, some essential properties, such as curing behavior, thermo-mechanical properties, and shape memory behavior were studied. Obtained biobased SMPs exhibit high potential for further tailoring of monomer molecules reflecting in adaptable mechanical properties and shape memory ability.

\section{Experimental}

\subsection{Materials}

Paraformaldehyde (96\%), resorcinol (96\%), octadecylamine ( $97 \%$; further marked as stearylamine), resorcinol diglycidyl ether (97\%; further marked as R-EP), chloroform (99\%), absolute ethanol ( $\geq 99 \%)$, sodium sulfate ( $96 \%$; further marked as $\mathrm{Na}_{2} \mathrm{SO}_{4}$ ) and sodium hydroxide ( $98 \%$; further marked as $\mathrm{NaOH})$ were used as received from Merck KGaA (Darmstadt, Germany).

\subsection{Synthesis of benzoxazine monomer}

Stearylamine $(26.9 \mathrm{~g}, 0.1 \mathrm{~mol})$, paraformaldehyde $(6.0 \mathrm{~g}, 0.2 \mathrm{~mol})$, and $250 \mathrm{ml}$ of chloroform were introduced into a $500 \mathrm{ml}$ round-bottom glass flask equipped with a reflux condenser, a thermometer, and a mechanical stirrer. After 30 minutes, $5.5 \mathrm{~g}$ 
( $0.05 \mathrm{~mol})$ of resorcinol was added, and the temperature of the reaction mixture was gradually increased up to $60^{\circ} \mathrm{C}$ and refluxed for approximately $20 \mathrm{~h}$. After that, the solvent was removed at reduced pressure, followed by washing several times with a $1 \mathrm{M}$ $\mathrm{NaOH}$ aqueous solution and deionized water. Subsequently, the solution was dried over anhydrous $\mathrm{Na}_{2} \mathrm{SO}_{4}$. The benzoxazine monomer was further purified by cold crystallization in absolute ethanol, filtered, and dried under vacuum. The white solid product ( $92 \%$ yield), obtained according to this process, was further referred to as RS-BOX.

IR ( $\mathrm{KBr}$ disk) $\left[\mathrm{cm}^{-1}\right]$ : 3500-3200 (-OH vibration), $1610(\mathrm{C}=\mathrm{C}$ benzene ring vibration), 1480 (tetrasubstituted benzene ring), 1345 ( $-\mathrm{CH}_{2}$ oxazine ring vibration), 1220 (C-O-C oxazine ring vibration), 930 and 870 (tetrasubstituted benzene ring).

${ }^{1} \mathrm{H} \mathrm{NMR}\left(\mathrm{CDCl}_{3}\right): \delta=6.55$ (aromatic protons), 4.75 and $3.90\left(\mathrm{Ar}-\mathrm{CH}_{2}-\mathrm{N}-\right.$, and $\left.-\mathrm{O}-\mathrm{CH}_{2}-\mathrm{N}-\right), 2.75-0.90$ (stearylamine aliphatic chain).

\subsection{Preparation of benzoxazine-epoxy bio-copolymers}

The benzoxazine monomer (RS-BOX) was mixed with epoxy resin (R-EP) to provide potential shapememory materials at various molar ratios of RSBOX:R-EP: 100:0, 80:20, 67:33, 50:50, 33:67 and 20:80. Afterward, the mixture with the desirable ratio was heated at $60^{\circ} \mathrm{C}$ in a glass beaker for approximately $15 \mathrm{~min}$ to yield a homogeneous mixture. Obtained molten resin was poured into a silicone mold and was completely thermally cured in an oven at 100 , 120 and $150^{\circ} \mathrm{C}$ for $2 \mathrm{~h}$ at each temperature and finally at $170^{\circ} \mathrm{C}$ for $10 \mathrm{~h}$. Finally, homogeneous dark brownish polybenzoxazine-epoxy crosslinked materials were obtained for all formulations, except 20:80 molar ratio, where some phase separation was detected.

\subsection{Characterization}

The formation and purity of resorcinol-based benzoxazine was confirmed by Fourier transform infrared spectroscopy (FT-IR) using $\mathrm{KBr}$ disks on Bruker IFS 66/S spectrometer (Billerica, USA) and by ${ }^{1} \mathrm{H}$ nuclear magnetic resonance (NMR) analysis on Bruker Avance III $500 \mathrm{MHz}$ spectrometer (Billerica, USA) at the temperature $296 \mathrm{~K}$ and frequency $500 \mathrm{MHz}$. Deuterated chloroform $\left(\mathrm{CDCl}_{3}\right)$ and 1,3,5-trimethoxybenzene were used as the solvent and internal standard, respectively.
Thermal properties and curing behavior of the RSBOX:R-EP samples were studied by differential scanning calorimetry (DSC). The measurements were performed on a Mettler Toledo DSC1 instrument with intra-cooler using STAR software. In and Zn standards were used for the temperature calibration and for the determination of the instrument time constant. Samples of around $10 \mathrm{mg}$ were weighed in standard $40 \mu \mathrm{l}$ alumina pans. A heating rate of $10^{\circ} \mathrm{C} / \mathrm{min}$ was used in the range from 0 to $350^{\circ} \mathrm{C}$ and the purge nitrogen gas flow was maintained at $30 \mathrm{ml} / \mathrm{min}$ for all experiments.

A Mettler Toledo DMA 861e dynamic mechanical analyzer was used to determine the dynamic storage modulus $\left(E^{\prime}\right)$, loss modulus $\left(E^{\prime \prime}\right)$ and loss factor $(\tan \delta)$, for cured RS-BOX:R-EP samples using tensile-testing mode. Measurements were performed on rectangular specimens with dimensions of approximately $10.0 \times 7.0 \times 1.0 \mathrm{~mm}$ by heating from -20 to $200^{\circ} \mathrm{C}$, at a heating rate of $2{ }^{\circ} \mathrm{C} / \mathrm{min}$ and frequency of $1 \mathrm{~Hz}$.

The shape memory properties of cured samples were qualitatively examined by a series of photos recorded in the shape recovery process for specimens deformed by bending mode. A rectangular molded sheet specimen with dimensions of approximately $10.0 \times 50.0 \times 2.0 \mathrm{~mm}$ was heated to a temperature above $T_{\mathrm{g}}$ for several minutes, transformed into a desirable shape, and cooled rapidly to room temperature under the constrained condition to fix the temporary shape. Then, the specimen was unloaded and heated back to the $T_{\mathrm{g}}$ to recover the permanent shape.

Besides, the shape memory abilities were quantitatively investigated under bending deformation mode. The bending shape memory behaviors were characterized by a fold-deploy test according to the literature $[20,23]$ with some modifications. A rectangular molded sheet specimen with dimensions of approximately $10.0 \times 50.0 \times 2.0 \mathrm{~mm}$ was heated to a temperature above $T_{\mathrm{g}}$, bent into a $\mathrm{U}$-shaped circling rod and finally cooled rapidly to room temperature to fix the temporary shape under a constant external force. Subsequently, the specimen was unloaded, and the device, which can measure the deflection angle of the free side of the U-shaped sheet, was placed in an oven at the desired temperature, and the shape recovery process was monitored. The folded angle $\left(\theta_{\max }\right.$, a fold angle of $120^{\circ}$ was made on all specimens due to specimen properties/restrictions), fixed angle $\left(\theta_{\text {fix }}\right)$, and residual angle $\left(\theta_{\mathrm{i}}\right)$ were 
measured, and the shape fixity ratio $\left(R_{\mathrm{f}}\right)$ and shape recovery ratio $\left(R_{\mathrm{r}}\right)$ were calculated by the Equations (1) and (2):

$$
\begin{aligned}
& R_{\mathrm{f}}=\frac{\theta_{\text {fix }}}{\theta_{\text {max }}} \cdot 100 \% \\
& R_{\mathrm{r}}=\frac{\theta_{\text {max }}-\theta_{\mathrm{i}}}{\theta_{\text {max }}} \cdot 100 \%
\end{aligned}
$$

Finally, the shape memory properties of chosen formulations were quantitatively investigated by thermomechanical cycles performed in a tensile deformation mode on a Mettler Toledo DMA 861e dynamic mechanical analyzer. A rectangular molded specimen with dimensions of approximately $10.5 \times 7.0 \times 2.0 \mathrm{~mm}$ was heated at a constant force of $1 \mathrm{~N}$ from room temperature to $T_{\mathrm{g}}$ (at a heating rate of $1{ }^{\circ} \mathrm{C} / \mathrm{min}$ ) and held at elevated temperature for $5 \mathrm{~min}$. Subsequently, the force was isothermally raised to $3.5 \mathrm{~N}$ (for RS-BOX:R-EP: 67:33), $4 \mathrm{~N}$ (for RS-BOX:R-EP: 50:50) or $5 \mathrm{~N}$ (for RS-BOX:R-EP: 33:67), increasing displacement. After that, the specimen was cooled back to room temperature under constant load to fix the temporary shape. To evaluate the shape fixity, the force was unloaded $(1 \mathrm{~N})$ at isothermal condition $(R T)$. Finally, the specimen was reheated back to $T_{\mathrm{g}}$ at a heating rate of $1{ }^{\circ} \mathrm{C} / \mathrm{min}$. The evolution of force, displacement and temperature enabled the determination of shape fixity $\left(R_{\mathrm{f}, \mathrm{DMA}}\right)$ and shape recovery $\left(R_{\mathrm{r}, \mathrm{DMA}}\right)$ ratios by the Equations (3) and (4):

$$
\begin{aligned}
R_{\mathrm{f}, \mathrm{DMA}} & =\frac{D_{\mathrm{u}, \mathrm{N}}-D_{\mathrm{r}, \mathrm{N}-1}}{D_{0, \mathrm{~N}}-D_{\mathrm{r}, \mathrm{N}-1}} \cdot 100 \% \\
R_{\mathrm{r}, \mathrm{DMA}} & =\frac{D_{\mathrm{u}, \mathrm{N}}-D_{\mathrm{r}, \mathrm{N}}}{D_{\mathrm{u}, \mathrm{N}}-D_{\mathrm{r}, \mathrm{N}-1}} \cdot 100 \%
\end{aligned}
$$

where $D_{0}, D_{\mathrm{u}}$ and $D_{\mathrm{r}}$ denote the displacement value after the stretching step (before unloading the specimen), after unloading and after recovery, respectively, for each individual cycle step $(N)$.

\section{Results and discussion}

\subsection{Synthesis and characterization of resorcinol based benzoxazine}

A synthesis of benzoxazine monomer precursors, based on naturally accessible chemicals, was performed by Mannich type polycondensation reaction between resorcinol, stearylamine and paraformaldehyde (Figure 1), according to our previous procedures [27,3 1]. The chemical structure of the benzoxazine

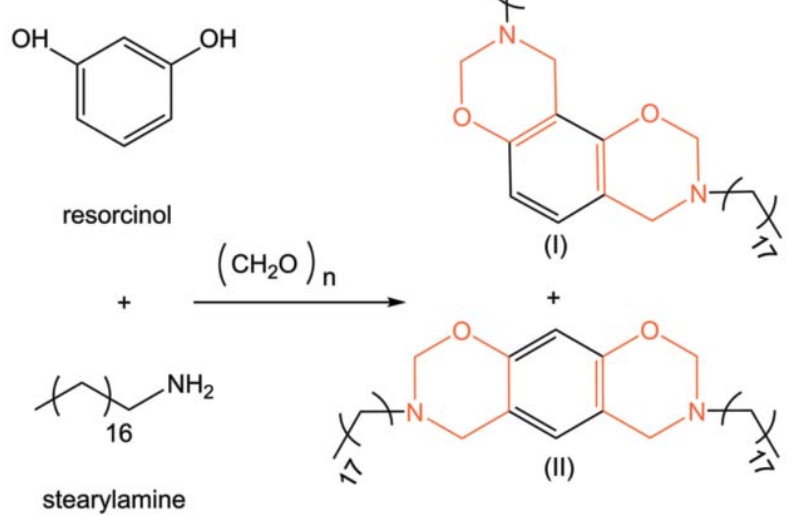

RS-BOX

Figure 1. Synthesis path of RS-BOX from bio-based starting materials: resorcinol, stearylamine and paraformaldehyde. According to the literature [28, 30], two isomeric species, namely asymmetric (I) and symmetric (II), can be formed.

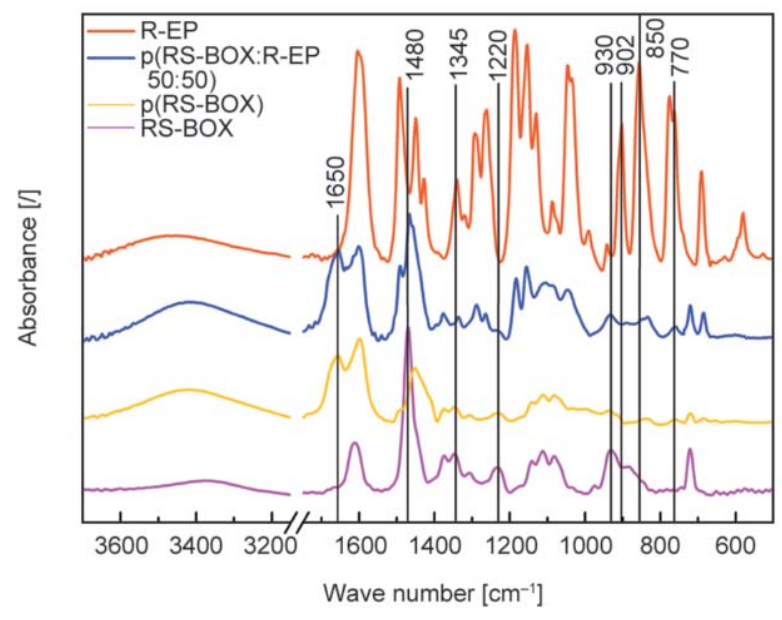

Figure 2. FT-IR spectra of RS-BOX monomer, RS-BOX polymer, R-EP monomer and RS-BOX:R-EP copolymer with equimolar ratio.

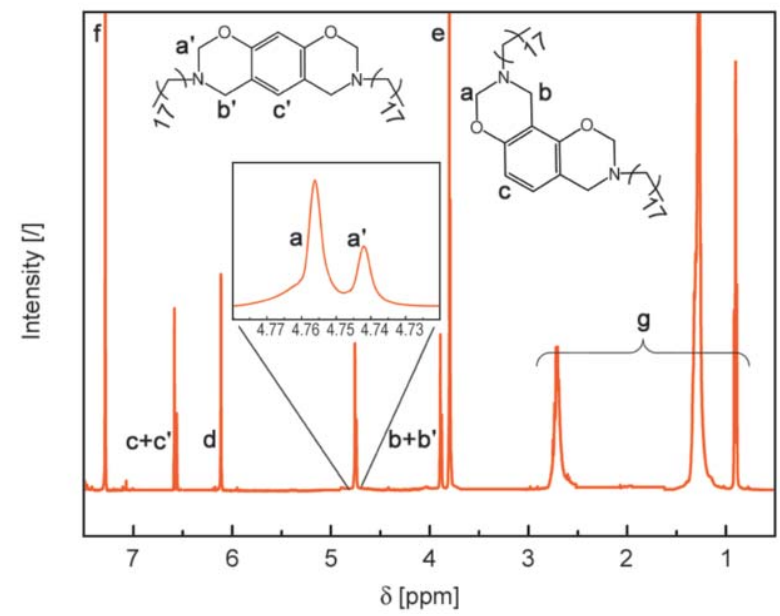

Figure 3. ${ }^{1} \mathrm{H}$ NMR of RS-BOX monomer with 1,3,5-trimethoxybenzene standard in $\mathrm{CDCl}_{3}$. 
(RS-BOX) was confirmed by FT-IR (Figure 2) and ${ }^{1} \mathrm{H}$ NMR (Figure 3) spectra.

The FT-IR spectra of RS-BOX showed the characteristic signal for oxazine ring at $1220 \mathrm{~cm}^{-1}$ (corresponding to the asymmetric stretching vibration of $\mathrm{C}-\mathrm{O}-\mathrm{C}$ group $)$ and at $1345 \mathrm{~cm}^{-1}\left(\mathrm{CH}_{2}\right.$ wagging into the closed benzoxazine ring) [34]. The formation of the tetra-substituted aromatic ring was further confirmed by typical signals at 1480,930 and $870 \mathrm{~cm}^{-1}$ $[26,32]$. The absorption band at $1610 \mathrm{~cm}^{-1}$ may be attributed to aromatic $\mathrm{C}=\mathrm{C}$ stretching vibrations of the benzene ring [26]. Moreover, some phenolic -OH stretching vibration was visible between 3200 and $3500 \mathrm{~cm}^{-1}$, indicating the part of benzoxazine monomers were only monofunctional and/or part of the benzoxazine rings had been already opened. In either case, free phenolic groups were formed. The ratio between bis-functional and monofunctional monomer was calculated from the ${ }^{1} \mathrm{H}$ NMR spectra, with detailed explanation later in the text.

The structure of the new benzoxazine RS-BOX was additionally confirmed by ${ }^{1} \mathrm{H}$ NMR spectra (Figure 3). The appearance of the protons resonating at $4.75 \mathrm{ppm}\left(\mathrm{O}-\mathrm{CH}_{2}-\mathrm{N}, \mathbf{a} / \mathbf{a}^{\prime}\right)$ and $3.90 \mathrm{ppm}$ ( $\left.\mathrm{Ar}-\mathrm{CH}_{2}-\mathrm{N}, \mathbf{b} / \mathbf{b}^{\prime}\right)$ was clear evidence of the benzoxazine ring formation. From the ratio between the area of the signals at $4.75 \mathrm{ppm}\left(\mathbf{a}+\mathbf{a}^{\prime}\right)$ and $6.55 \mathrm{ppm}\left(\mathbf{c}+\mathbf{c}^{\prime}\right)$ the ring-closing degree was calculated, according to the method proposed by Sawaryn et al. [35]. The calculated ratio was approximately $85 \%$, meaning $15 \%$ of the synthesized monomers were monofunctional and so carrying only one polymerizable unit. Nevertheless, monofunctional monomer molecules should still copolymerize efficiently. These findings were in good agreement with FT-IR spectra (Figure 2), where free hydroxyl groups were detected as well. The NMR spectra indicated the formation of both isomeric forms, with a ratio between asymmetric (a) and symmetric $\left(\mathbf{a}^{\prime}\right)$ being 3:1. Similar data, with an even higher proportion of asymmetric isomer $(7: 1)$, were published by Hartwig and coworkers [32, 33]. On the contrary, the NMR data of resorcinol-based benzoxazine, synthesized by Dumas et al. [26], was undistinguishable for isomeric ratio determination. The prolonged reaction time employed in our case ( $20 \mathrm{~h}$ ), compared to 1 or $5 \mathrm{~h}$ used by Hartwig and his group [32, 33], along with different amine components used, might result in a different isomeric ratio. Benzoxazine purity was determined by comparing the area of oxazine characteristic signals $\left(\mathbf{a}+\mathbf{a}^{\prime}\right.$ and $\left.\mathbf{b}^{+} \mathbf{b}^{\prime}\right)$ and area of 1,3,5-trimethoxybenzene standard signals, observed at $6.10 \mathrm{ppm}(\mathbf{d})$ and $3.80 \mathrm{ppm}(\mathbf{e})$, giving a value of $91 \%$. The other signals belong to protons in a solvent (chloroform; $7.20 \mathrm{ppm}$, marked with $\mathbf{f})$ and in stearylamine aliphatic chain $(2.75$, 1.30 and $0.90 \mathrm{ppm}$, marked with a $\mathbf{g}$ ).

\subsection{Polymerization and curing behaviour of BOX/EP mixtures}

The polymerization behavior of BOX/EP mixtures was first studied by FT-IR analysis, depicted in Figure 2. After the curing, the characteristic absorption bands associated with the benzoxazine monomer (oxazine ring, $\mathrm{CH}_{2}$ wagging, the asymmetric and symmetric stretching of $\mathrm{C}-\mathrm{O}-\mathrm{C}$ ) partially or completely disappeared (FT-IR spectra of $\mathrm{p}(\mathrm{RS}-\mathrm{BOX})$ ), indicating the progression of the ring-opening process. Meanwhile, the absorption peak of tetrasubstituted benzene ring $\left(1480 \mathrm{~cm}^{-1}\right)$ shifted to $1470 \mathrm{~cm}^{-1}$ due to the substitution crosslinking reaction, showing that the Mannich bridge linkage was produced by the oxazine-ring opening polymerization [36, 37]. The band at $1650 \mathrm{~cm}^{-1}$ is attributed to intramolecular hydrogen-bonded-OH groups [36], formed by epoxy and benzoxazine ring opening. The formation of phenolic groups, via BOX/EP ring opening, can be confirmed by characteristic absorption peak at $3400 \mathrm{~cm}^{-1}$. The peaks at 902,850 and $770 \mathrm{~cm}^{-1}$ [38], observed in R-EP spectra, are typical of an epoxy group and almost completely disappear after thermal curing and copolymerization.

Further on, the thermal properties and curing behavior of each benzoxazine/epoxy mixture were investigated by DSC analysis (Figure 4a). All formulations show an endothermic peak with the minimum at $47^{\circ} \mathrm{C}$ which refers to the melting of RS-BOX. Consequently, the enthalpy of the melting decreases by lowering the amount of RS-BOX in the mixture, since it simply follows the rule of mixture. Furthermore, the stretched exothermic peak, indicating on the curing process, takes place at elevated temperatures with the onset temperature of approximately $140^{\circ} \mathrm{C}$. The normalized responses of the curing process are further shown in Figure 4b, indicating that an exothermal signal consisted of several overlapped peaks and thus representing a complex curing mechanism. Additionally, the enthalpy of the curing increases with a greater amount of R-EP in the mixture, which signifies that R-EP has an important role in the curing process (Table 1). To understand the 

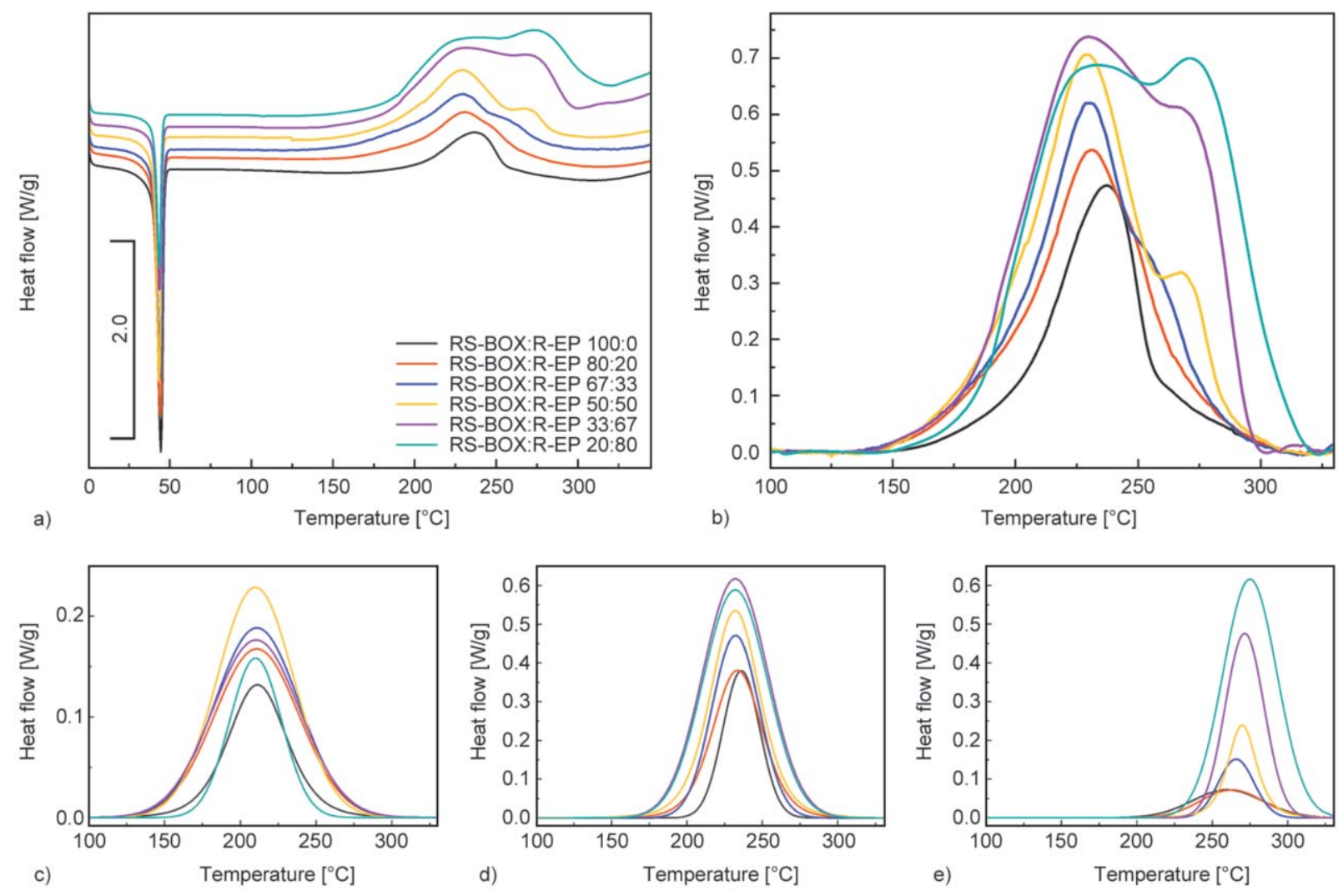

Figure 4. DSC thermograms (a) and normalized DSC thermograms focused only on the exothermic peak (b) at various RSBOX:R-EP compositions: 100:0, 80:20, 67:33, 50:50, 33:67 and 20:80. Normalized DSC thermograms were deconvoluted to acquire three separated peaks (c-e) each indicating an individual reaction.

mechanism behind the curing process, overlapped peaks were further deconvoluted by Gaussian distribution $[39,40]$ and the possible reaction scheme was constructed (Figure 5). In such a way, three individual peaks were identified representing three possible reactions during curing (Figures $4 \mathrm{c}-4 \mathrm{e}$ ).

The mechanism of the neat RS-BOX curing (black line) is related to the reaction among the RS-BOX monomers [41]. The first peak (reaction 1.1) belongs to the accelerated oxazine ring-opening in the presence of hydroxyl groups. The FT-IR (Figure 2) and ${ }^{1} \mathrm{H}$ NMR (Figure 3 ) analyses demonstrated the existence of benzoxazine species with free $-\mathrm{OH}$ groups, acting as a catalyst for the ring-opening of oxazine [41]. Next, the second deconvoluted peak (reaction 2.1) is assigned to the thermally accelerated ringopening accompanied by an autocatalytic reaction of benzoxazine monomer. Finally, the third deconvoluted peak is associated with the diffusion-controlled step in the curing reaction due to the sterical hindrance of large, partly polymerized molecules [41].

Nevertheless, when RS-BOX was mixed with the $\mathrm{R}-\mathrm{EP}$, the mechanism of the curing process changed. Consequently, minor changes in the interpretation of deconvoluted peaks appeared. The first peak could still be explained by accelerated oxazine ring-opening

Table 1. Enthalpies $(\Delta H)$ and peak temperatures $\left(T_{\mathrm{p}}\right)$ for deconvoluted overlapped peaks obtained from DSC thermograms at various RS-BOX:R-EP compositions: 100:0, 80:20, 67:33, 50:50, 33:67 and 20:80.

\begin{tabular}{|c|c|c|c|c|c|c|c|}
\hline \multirow[t]{2}{*}{ Sample } & \multicolumn{4}{|c|}{$\begin{array}{c}\Delta H \\
{[\mathrm{~J} / \mathrm{g}]}\end{array}$} & \multicolumn{3}{|c|}{$\begin{array}{c}T_{\mathbf{p}} \\
{\left[{ }^{\circ} \mathbf{C}\right]}\end{array}$} \\
\hline & Overall & Peak 1 & Peak 2 & Peak 3 & Peak 1 & Peak 2 & Peak 3 \\
\hline $100: 0$ & 135.3 & 40.9 & 69.9 & 25.4 & 211.3 & 236.0 & 259.8 \\
\hline $80: 20$ & 190.2 & 70.6 & 98.2 & 22.4 & 210.7 & 233.4 & 262.7 \\
\hline $67: 33$ & 216.6 & 78.7 & 110.0 & 26.8 & 210.8 & 232.2 & 265.9 \\
\hline $50: 50$ & 263.4 & 86.9 & 140.7 & 37.9 & 209.9 & 231.9 & 269.8 \\
\hline $33: 67$ & 364.9 & 76.3 & 201.0 & 92.4 & 210.3 & 232.1 & 271.5 \\
\hline $20: 80$ & 399.2 & 40.8 & 188.7 & 165.9 & 210.1 & 231.9 & 274.9 \\
\hline
\end{tabular}



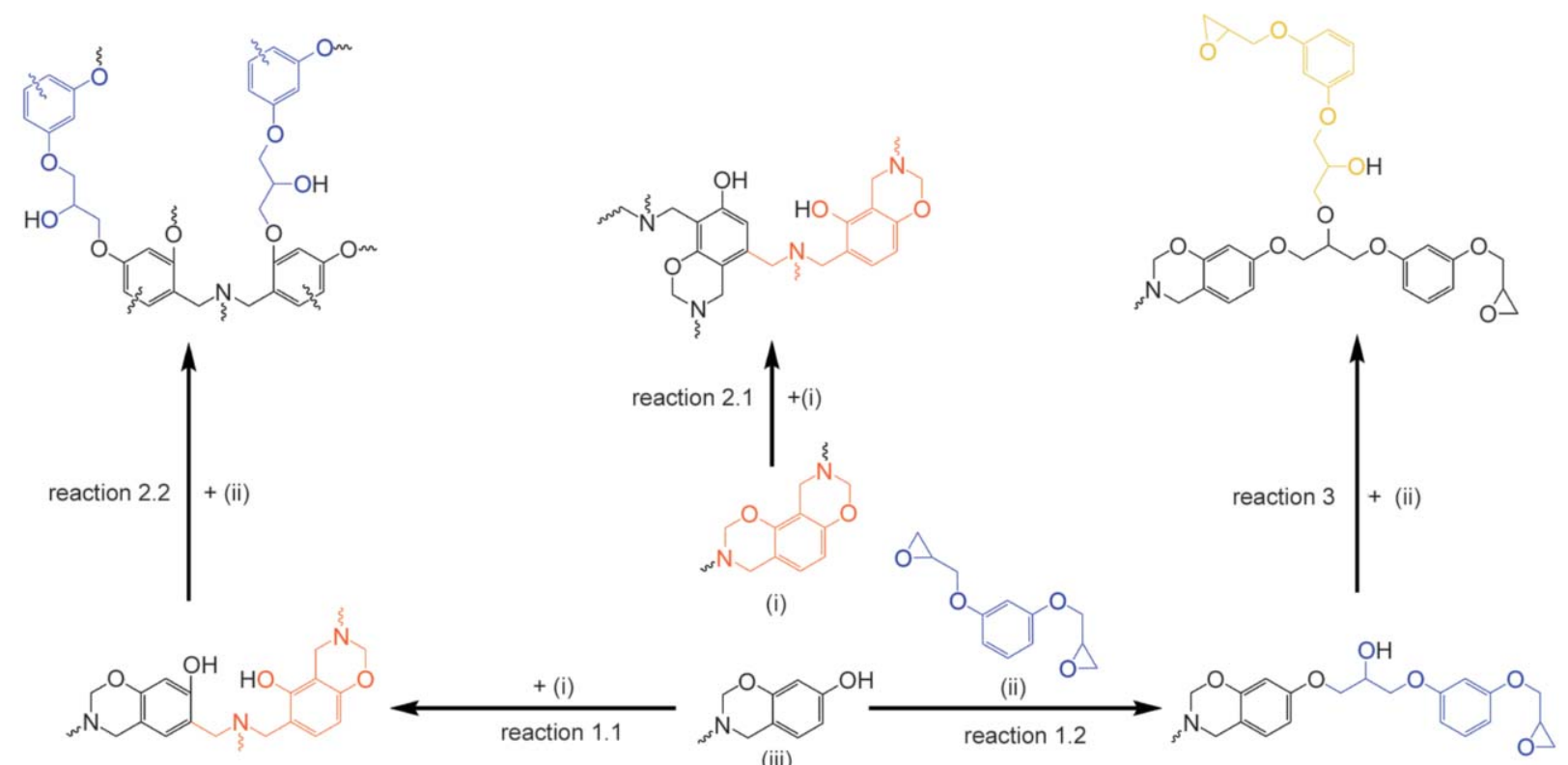

(iii)

Figure 5. RS-BOX and R-EP curing mechanisms: reaction 1 - catalytic opening of oxazine ring (reaction 1.1) and epoxy group (reaction 1.2) by free hydroxyl groups, reaction 2.1 - thermally accelerated oxazine ring opening and autocatalytic reaction, reaction 2.2 - etherification reaction between hydroxyl groups of opened polybenzoxazine and an epoxide, and reaction 3 - epoxy homopolymerization (etherification).

with the presence of free hydroxyl groups (reaction 1.1), although the peak enthalpy intensifies with the decrease of benzoxazine in the reaction mixture. The observed could be explained by the accelerated opening of the epoxy group again due to the presence of monofunctional benzoxazines with free hydroxyl groups (reaction 1.2). The highest enthalpy of the reaction 1 was achieved for the mixture RS-BOX:R-EP 50:50 followed by the decrease of the enthalpy with a lesser amount of RS-BOX. From the trend of enthalpy increase and decrease, it can be concluded that the reaction of the accelerated epoxy opening is more exothermic than the reaction of accelerated oxazine ring-opening. Also, by lowering the amount of RS-BOX, a lesser amount of hydroxyl groups were available to accelerate the opening of the epoxy group, which is why the trend turned at some degree. The second peak (reaction 2) is now a connection of two effects: autocatalytic reaction of the benzoxazine monomer (reaction 2.1) accompanied by the etherification reaction between hydroxyl groups of polymerized benzoxazine resin and an epoxide (reaction 2.2) [42,43]. The reaction steadily increases and achieves the highest value for the mixture RS-BOX:R-EP 33:67, when a slight drop in the enthalpy can be observed (Figure 4d, Table 1). Obviously, the enthalpy of the benzoxazine autocatalytic reaction is less significant than etherification. The third peak (reaction 3) can be associated with the polymerization of the epoxide group (homopolymerization) [44], which generally appears at higher temperatures (Figure 4e, Table 1). By increasing the amount of the R-EP in the reaction mixture, the enthalpy increases and the temperature of the peak is slowly moving to the right, reaching the highest values at $274.9^{\circ} \mathrm{C}$ for RS-BOX:R-EP 20:80. On the other hand, reaction 1 and reaction 2 exhibit similar values of the peak temperature, approximately 211 and $232{ }^{\circ} \mathrm{C}$, respectively. According to the results, the RS-BOX can simultaneously act as a curing agent and a stable/rigid network segment in this two-component system, which can have a significant impact in further system formulation. The cured samples were used for all further material investigations.

\subsection{Dynamic mechanical properties}

Dynamic mechanical analysis (DMA) was introduced to investigate the mechanical properties of crosslinked samples, since thermally assisted shapememory materials should possess certain specific thermo-mechanical properties, such as high molecular and chain flexibility with sufficient bending strength $[13,23,24]$. The material shape transition is typically controlled by the temperature window of the glass transition process. Therefore, a wide, but sharp $T_{\mathrm{g}}$ transition should be beneficial for processing purposes. The glass transition windows of cured benzoxazine-epoxy copolymers were examined in a 

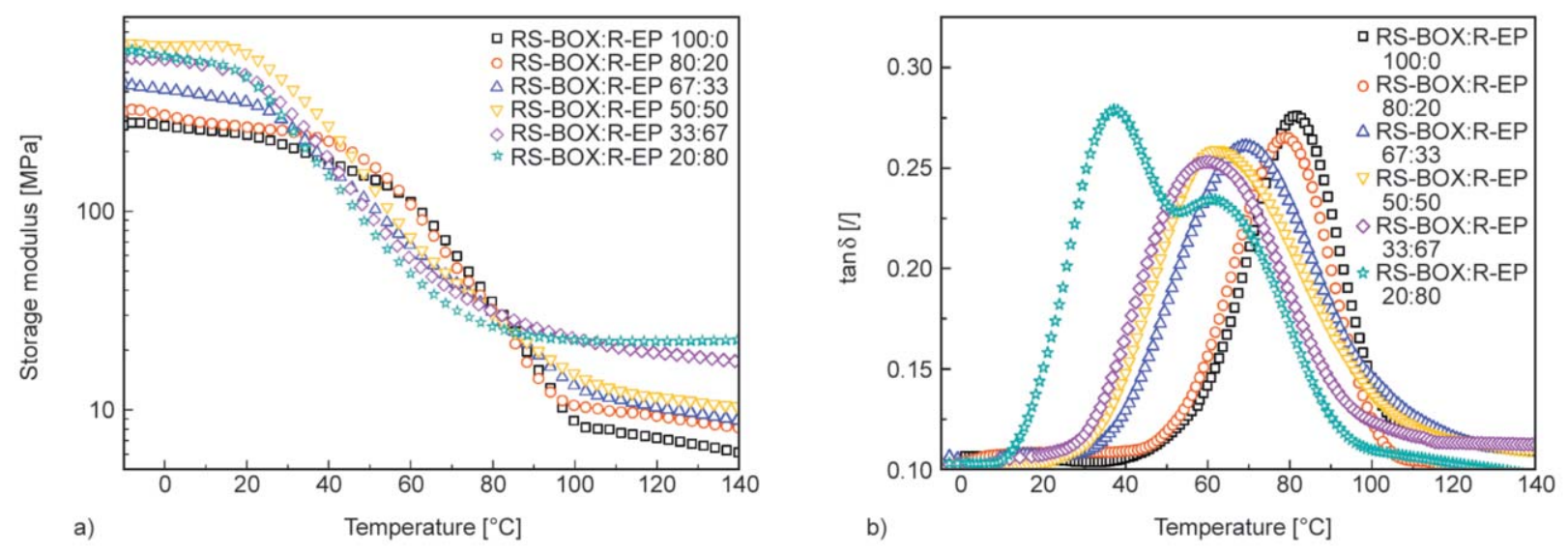

Figure 6. Storage modulus $\left(E^{\prime}\right)$ in tensile mode (a) and loss factor/tan $\delta$ peak (b) at various RS-BOX:R-EP compositions: 100:0, 80:20, 67:33, 50:50, 33:67 and 20:80.

tensile mode deformation. The conventional DSC measurements of cured samples did not allow $T_{\mathrm{g}}$ determination as no significant capacity variation was observed during cured samples heating. Besides, exothermic peaks, observed in DSC runs of uncured samples (Figure 4), wholly disappeared (data are not shown), indicating a complete curing process.

Figure 6 shows temperature plots of storage modulus $\left(E^{\prime}\right)$ and loss factor $(\tan \delta)$ as a function of the benzoxazine-epoxy formulations. The glass transition from the glassy region at lower temperatures to rubbery plateau at higher temperatures is clearly noticeable for all storage modulus curves. The storage moduli in its glassy state tended to increase with increasing R-EP content in copolymer materials (Table 2), indicating that the material stiffness should also be enhanced. For example, the value of $E^{\prime}$ at $20^{\circ} \mathrm{C}$ increased from 240 to $530 \mathrm{MPa}$ when the amount of R-EP in material increased from 0 to $80 \%$. This phenomenon is due to the more rigid characteristic of R-EP resins compared to RS-BOX, which has a more flexible chemical structure, as a consequence of two long aliphatic chains form stearylamine. Interestingly, the highest glassy storage modulus was observed for RS-BOX:R-EP 50:50 sample. Two types of highly compatible polymeric chains (BOX and EP) in equimolar composition might form a stiffer copolymeric network, leading to higher storage modulus. Besides, storage moduli in the rubbery region systematically increased with increasing R-EP content as well, suggesting an enhancement of the crosslinking density in the final copolymeric matrix. The statistical theory of rubber elasticity [23, 24, 44] states that the rubbery plateau is associated with the crosslinking density of the materials and can be estimated from the rubbery plateau modulus according to the following Equation (5):

$\rho=\frac{E_{\mathrm{R}}^{\prime}}{3 \varphi R T}$

where $E_{R}^{\prime}$ is the equilibrium elastic modulus in the rubbery region, $\varphi$ is the front factor, which is unity for ideal rubbers, $R$ is the gas constant, $T$ is the absolute temperature, and $\rho$ is the crosslinking density. Crosslinking densities (Table 2), calculated according to Equation (5), represent the molarity of network

Table 2. Thermo-mechanical properties of RS-BOX:R-EP copolymers, at various RS-BOX:R-EP compositions: 100:0, 80:20, 67:33, 50:50, 33:67 and 20:80, based on DMA curves.

\begin{tabular}{|c|c|c|c|c|c|c|}
\hline Sample & $\begin{array}{c}E^{\prime} \text { at } R T \\
\text { [MPa] }\end{array}$ & $\begin{array}{c}E^{\prime} \text { at rubbery } \\
\text { plateau }\end{array}$ & $\begin{array}{c}\rho\left(\cdot 10^{-3}\right) \\
{\left[\mathrm{mol} \cdot \mathrm{cm}^{-3}\right]}\end{array}$ & $\begin{array}{l}T_{\mathrm{g}}^{\mathrm{a})} \\
{\left[{ }^{\circ} \mathrm{C}\right]}\end{array}$ & $\tan \delta$ width $\left.^{b}\right)$ & $\begin{array}{c}\tan \delta \text { area } \\
{[-]}\end{array}$ \\
\hline 100:0 & 240 & 7.5 & 0.84 & 83 & 25 & 10.74 \\
\hline $80: 20$ & 300 & 9.8 & 1.11 & 79 & 30 & 11.63 \\
\hline $67: 33$ & 420 & 12.4 & 1.45 & 70 & 40 & 16.37 \\
\hline $50: 50$ & 580 & 15.2 & 1.80 & 65 & 45 & 21.84 \\
\hline $33: 67$ & 510 & 21.2 & 2.54 & 62 & 40 & 17.01 \\
\hline $20: 80$ & 530 & 22.3 & 2.68 & $37 / 61$ & $60^{\mathrm{c})}$ & $18.05^{\mathrm{c})}$ \\
\hline
\end{tabular}

a) based on $\tan \delta$ peak

b) determined at half height $\tan \delta$ peak

c) determined together for both peaks 
chains per volume unit of the copolymers $[23,24$, 44]. The crosslinking density tended to increase with an increasing epoxy content due to differences in the chemical structure of both neat polymers, since benzoxazine side aliphatic chains did not contribute to additional networking, leading to less crosslinked copolymeric structure.

Moreover, Table 2 lists the temperature of $\tan \delta$ peaks with its width, enabling determination of glass transition temperature and its transition range, respectively. A single peak of loss factor was detected for all formulations, except for 20:80, where two distinct peaks were observed. This is most likely due to the phase separation process that occurred during the copolymerization process. Therefore, the low-temperature peak $\left(37^{\circ} \mathrm{C}\right)$ probably indicates the glass transition of neat epoxy, while the high-temperature peak $\left(61^{\circ} \mathrm{C}\right)$ may indicate the glass transition of the BOX-EP copolymer. Nevertheless, the glass transition temperatures, determined at $\tan \delta$ peak maximum, increased in parallel with increasing benzoxazine content. Higher intramolecular and intermolecular interactions presented in the polybenzoxazine matrix caused an increase of $T_{\mathrm{g}}$ that is in good agreement with results published elsewhere [17]. However, the strength of physical interactions is considerably lower compared to chemical, covalent interactions (predominant in the epoxy matrix) [13], resulting in a more pronounced decrease of a storage modulus in a glassy state with higher RS-BOX amount. A transition range gives the temperature window where material softens and can be potentially designed and redesigned. A broader area of glass transition and/or multiple $T_{\mathrm{g}}$ are essential properties of materials that may possess (multiple) shape memory ability [45]. In our case, incorporation of R-EP in the RS-BOX matrix resulted in an increase of the width of the $\tan \delta$ peak, until an equimolar ratio was reached (50:50). After that, the peak width started to decrease slightly. This can be due to the fact that RS-BOX: R-EP 50:50 had the most heterogeneous nature and subsequently the wider glass transition window. In addition, the height of the $\tan \delta$ peak, which is somehow in inverse proportion with a value of crosslinking density, decreased with increasing EP amount and is therefore in excellent agreement with crosslinking density calculations.

The $\tan \delta$ represents the ratio of the viscous to elastic response $\left(E^{\prime \prime} / E^{\prime}\right)$ in a viscoelastic material, meaning potential of the material to lose or absorb energy [45,
46]. The total amount of energy that can be absorbed by a material is related to the area under the $\tan \delta$ curve. A large $\tan \delta$ area indicates a high degree of molecular mobility during glass transition, which translates into better damping properties, resulting in better energy absorbance/loss of the material [46]. Therefore, larger areas under the $\tan \delta$ curve should be required for a shape memory ability. Results of $\tan \delta$ curves integration, listed in Table 2, indicate that R-EP rich materials should absorb more energy since the largest $\tan \delta$ curve area was determined for RS-BOX:R-EP 50:50 copolymer. Note that two separate peaks disabled the exact integration of the $\tan \delta$ curve for RS-BOX:R-EP 20:80 sample. In conclusion, the DMA results suggested that shape-memory materials based on RS-BOX and R-EP could be designed. The material with equimolar RS-BOX:R-EP ratio proved to have the highest potential for SMP design since excellent mechanical strength (necessary for a good shape fixity) was combined with a high amount of absorbed energy during transformation along with sufficient rubbery modulus and crosslinking density (necessary for a good shape recovery).

\subsection{Shape memory properties}

The shape-memory properties of the polybenzoxazine-epoxy copolymers were first qualitatively examined by different bending modes. Results demonstrate that all materials exhibit the one-way dualshape memory effect. The shape fixity $\left(R_{\mathrm{f}}\right)$ and shape recovery $\left(R_{\mathrm{r}}\right)$ ratios define the material shape memory ability and are typically determined from thermomechanical cycles. The $R_{\mathrm{f}}$ quantifies the ability of the material to fix the temporary shape, whereas $R_{\mathrm{r}}$ measures its ability to recover the permanent shape $[25,47]$. The difference in mechanical properties between hard and soft segments in shape memory material above and below the switching temperature contributes to both phenomena. A high glassy state modulus shall provide a material with a high shape fixity during simultaneous cooling and unloading, while a high rubbery modulus should provide a high elastic recovery at high temperature [47]. Therefore, a high storage modulus ratio between its value in glassy and rubbery plateau should allow easy shaping of material at $T>T_{\mathrm{g}}$ and high material resistance to deformation at $T<T_{\mathrm{g}}[20,48]$. The shape fixity, with respect to storage modulus, was calculated by the Equation (6) proposed by Kim et al. [48]: 
$R_{\mathrm{f}}=\left(1-\frac{E_{\mathrm{r}}^{\prime}}{E_{\mathrm{g}}^{\prime}}\right) \cdot 100 \%$

where storage modulus ratios were determined at temperatures of $50^{\circ} \mathrm{C}$ below and above $T_{\mathrm{g}}$ value. The shape fixity values were in a very similar range $(97 \pm 0.8 \%)$ for all formulations except for sample RS-BOX:R-EP 50:50, where $R_{\mathrm{f}}$ value up to $99 \%$ was achieved. The results, which corresponds to the shape fixity of an epoxy [48] and epoxy-benzoxazine [20] systems reported elsewhere, demonstrated that all copolymers should be able to retain temporary shape and were in good agreement with the results of qualitative bending tests. Besides, fold-deploy tests were employed to further investigate the shape fixity and shape recovery angles. The sample was heated up to its transition temperature $\left(T \geq T_{\mathrm{g}}\right)$ and bent into the U-shape sheet with an angle of $120^{\circ}$. The fixed sample was subsequently cooled to room temperature in a water bath under constant external force and then held for $20 \mathrm{~min}$ to ensure that the sample retained its U-shape. Once the external force was released, the shape fixity was determined. In the next step, the bent sample was placed in a heating chamber and its shape recovery performance was evaluated. The characteristic angles $\left(\theta_{\max }, \theta_{\text {fix }}\right.$ and $\left.\theta_{\mathrm{i}}\right)$ were estimated to enable calculation of $R_{\mathrm{f}}$ and $R_{\mathrm{r}}$ according to Equation (1) and (2), respectively. All calculated $R_{\mathrm{f}}$ values were in the range between 95 and $100 \%$, similar to the ones calculated based on storage moduli. On the other hand, shape recovery $\left(R_{\mathrm{r}}\right)$ reflects how well the original shape of the material has been memorized $[25,47]$. Figure 7 shows a series of images for RS-BOX:R-EP 50:50 specimen during such shape recovery process at temperature $T_{\mathrm{g}}+20^{\circ} \mathrm{C}$ (approximately $\left.90^{\circ} \mathrm{C}\right)$. The fold angle $\left(120^{\circ}\right)$ was completely recovered in $700 \mathrm{~s}$, resulting in $100 \%$ shape recovery. All other investigated materials showed similar $R_{\mathrm{r}}$ performance as illustrated for the equimolar benzoxazine-epoxy ratio, yet with different recovery times. However, materials with low R-EP content (at or below $20 \mathrm{~mol} \%$ ) did not possess sufficient material strength to follow its recovery process fully. In other words, the material was not able to retain its temporary (recovery) shape in full since the recovery process was too fast. Therefore, some additional bending, which gradually returned to its original state, was observed during the recovery process. Nevertheless, the presented findings were in good agreement with DMA results, where the noticeable lower storage moduli were measured for benzoxazine-rich materials, indicating lower strength of such materials due to the unique chemical structure of (p)RS-BOX with a longer distance between individual crosslink points.

The shape recovery times were strongly influenced by material composition, as signifies Figure 8 . The higher the RS-BOX ratio, the faster the recovery process. The shape recovery depends on both the structure of the polymer and the thermo-mechanical
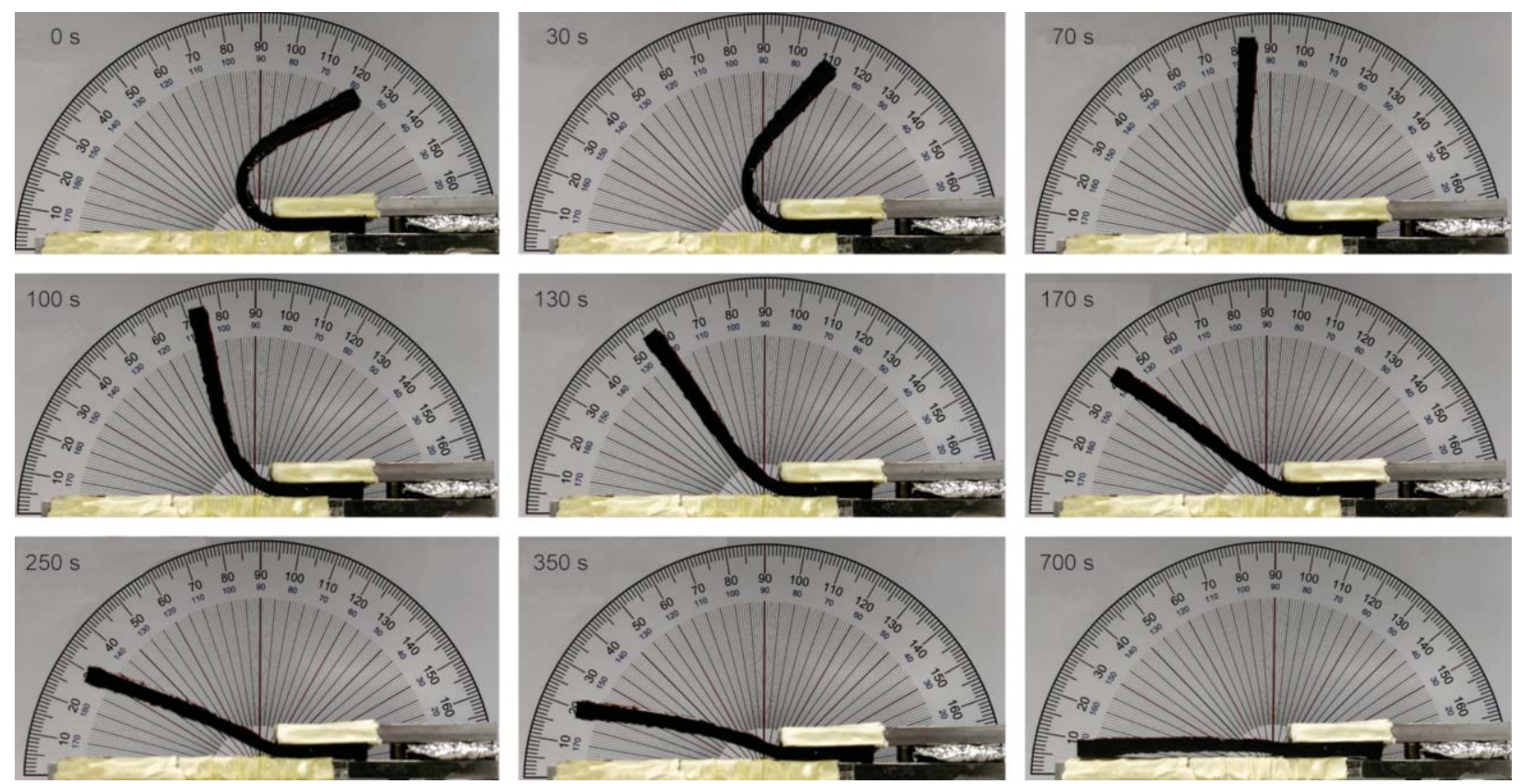

Figure 7. The series of images showing the shape recovery of the RS-BOX:R-EP 50:50 specimen at $T_{\mathrm{g}}+20^{\circ} \mathrm{C}\left(85^{\circ} \mathrm{C}\right)$. The permanent and temporary shapes were a straight and $120^{\circ} \mathrm{U}$-shape rectangle, respectively. 


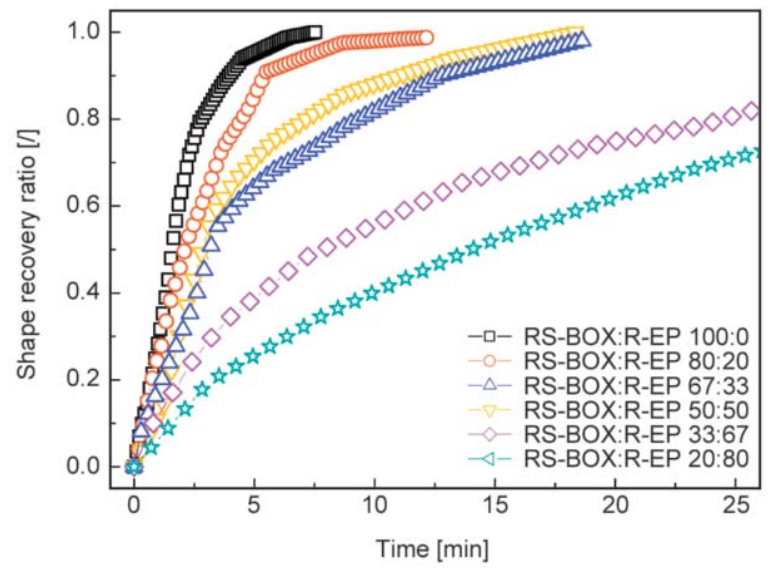

Figure 8. The shape recovery ratio as a function of recovery time at $T_{\mathrm{g}}$ as recovery temperature at various RSBOX:R-EP formulations: 100:0, 80:20, 67:33, 50:50, 33:67 and 20:80.

conditions of shape memorization [20, 24]. Therefore, the movements of the chain segments in RS-BOXrich materials were accelerated due to the lower crosslinking density of neat RS-BOX, which resulted in an increase of molecular weight between crosslink points. Accordingly, narrow glass transitions were noticed for the copolymers with higher RS-BOX content which translated to sharper shift from glassy to the rubbery region. As a consequence, the more constrained force can be released in a shorter period, resulting in reducing the recovery time. For example, the recovery time increased from 6 to $30 \mathrm{~min}$ when epoxy content increased from 0 to $80 \mathrm{~mol} \%$. Furthermore, the shape memory of RS-BOX rich materials was not triggered only by the elastic energy stored in crosslinked domains but also by the regeneration of relatively strong physical bonds, such as hydrogen bonds, which are strongly present in the polybenzoxazine matrix [14]. As a consequence, recovery time decreases. The times required for a complete recovery for RS-BOX:R-EP 67:33 and 50:50 were similar due to the comparable mechanical properties in the rubbery region (range of glass transition and value of storage modulus, Figure 6). Nevertheless, all compositions exhibited typical shape recovery curves. After the initial stage, their slopes steadily increased until terminal stages were reached. Afterward, the shape recovery rate was reduced since most of the constrained force had already been released. In conclusion, the addition of RS-BOX can significantly affect the shape recovery time; therefore final material properties can be tailored by suitably varying the starting formulation. Still, the effects

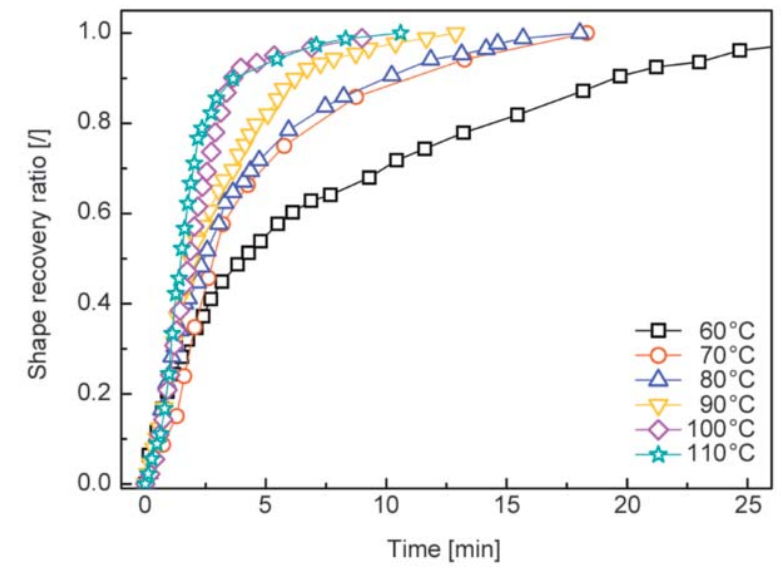

Figure 9. The shape recovery ratio as a function of recovery time at different recovery temperatures for RSBOX:R-EP 50:50.

of the formulation on the correlation between mechanical strength (loss with higher RS-BOX content) and recovery time (increased with higher RS-BOX content) should be taking into consideration when one develops a material design strategy.

The RS-BOX:R-EP 67:33; 50:50 and 33:67 were selected as model materials for all further shape memory tests since they showed the suitable shape recovery times without significant loss of mechanical strength. On the other hand, shape recovery of RS-BOX:R-EP 20:80 was too slow, while BOX rich samples had mechanical strength issues. The temperature effect on the shape recovery is shown in Figure 9 (for equimolar composition). Similar behavior was determined for the two other compositions (data not shown). In line with other papers [21, 23, 24], the shape recovery time was reduced by increasing the recovery temperature. The shape recovery of the SMPs depended on the relaxation of chain segments. At high temperature, the movement of chain segments became more intense, which caused an increase in the recovery force on the samples [47]. As a consequence, the shape recovery time of the specimens decreased with an increase in recovery temperature. Furthermore, the complete $(100 \%)$ shape recovery ratio was observed for all recovery conditions.

Permanent shape-memory ability along with good thermal stability is an important issue, especially for thermally switchable SMPs. To evaluate the shape memory performance after repeated transformation, the fold-deploy test was repeated multiple times. The results, displayed in Figure 10, show similar profiles of shape recovery curves, during multiple cycles. This 


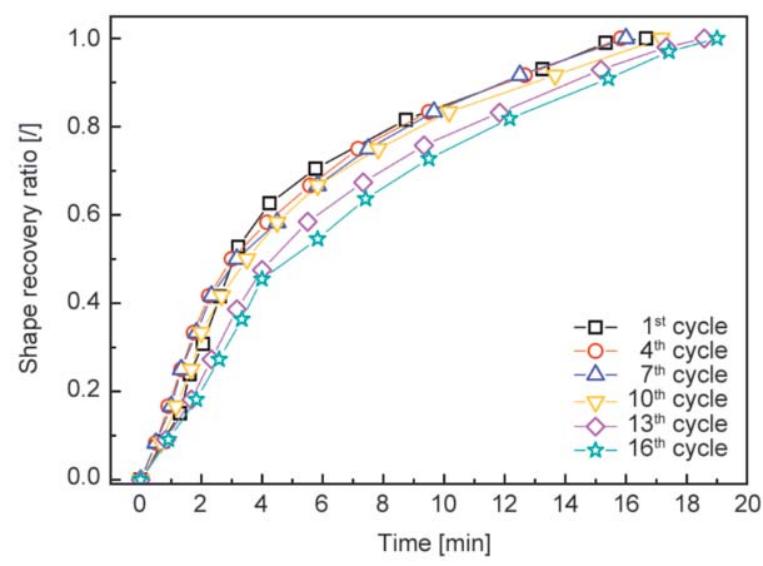

Figure 10. The shape recovery ratio as a function of recovery cycles for RS-BOX:R-EP 50:50 at a recovery temperature $70^{\circ} \mathrm{C}$.

signifies only marginal shape recovery loss through several shape transformations by heating the same material (RS-BOX:R-EP 50:50) above its softening point. Similar was observed for other copolymers with different formulations (data not shown).

In addition to fold-deploy cycles, the evolution of force, displacement, and temperature was determined by three thermo-mechanical cycles in a tensile deformation mode (Figure 11). The shape recovery and fixity ratios were calculated based on Equation (3) and (4) by estimation of loading, unloading and residual (unrecovered) displacement for each individual DMA cycle. An epoxy addition improved $R_{\mathrm{f}}$ values from 84 to $97 \%$ (for $1^{\text {st }}$ cycle) while on the other hand, slowed down the transition process due to the higher storage modulus and consequently more rigid structure (Figure 6). Furthermore, the shape fixity ratio decreased slightly by the number of the cycles, e.g., values of $R_{\mathrm{f}}$ for RS-BOX:R-EP 50:50 sample (Figure 11b) were $91.4,84.0$ and $83.9 \%$ for $1^{\text {st }}, 2^{\text {nd }}$ and $3^{\text {rd }}$ cycle, respectively, meaning the material should be able to retain most of the temporary shape. Yet, rather low storage modulus value, resulting in the reduction of the material elastic response, compared to other relevant duromeric systems, might prevent complete fixity. The reinforcement of biocopolymeric matrix should be beneficial for higher $R_{\mathrm{f}}$ values.

Interestingly, the shape recovery ratio, relative to the previous cycle, increased with each cycle for all three formulations: namely from 77 to $97 \%$ for $67: 33 \mathrm{com}$ positions, from 71 to $97 \%$ for $50: 50$ composition and from 87 to $96 \%$ for $33: 67$ composition. It appears that the material recovered its prior shape superbly, once it was transformed through the first deformation
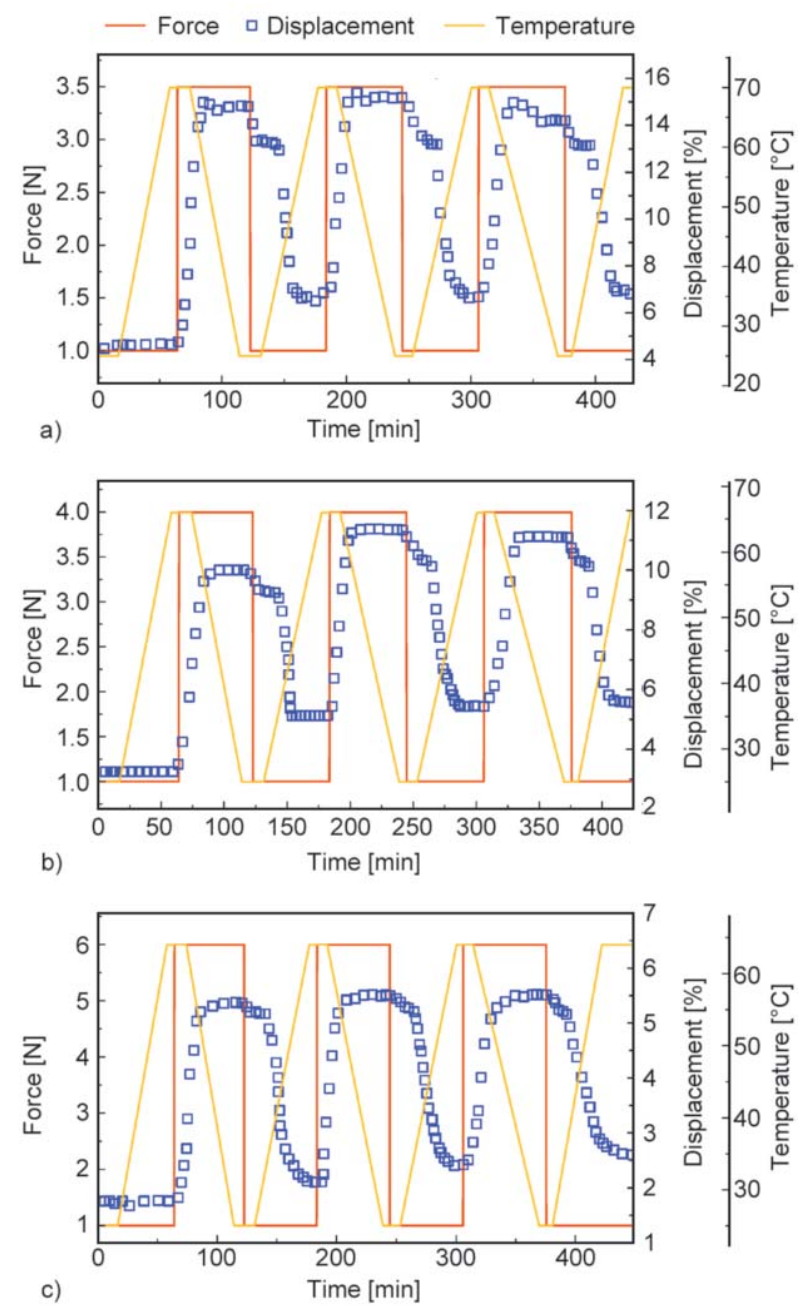

Figure 11. The evolution of force, displacement, and temperature with a time determined by DMA cycles in a tensile mode for RS-BOX:R-EP 67:33 (a), RS-BOX:R-EP 50:50 (b) and RS-BOX:R-EP 33:67 (c). Note that the displacement [\%] represents the ratio between operational displacement determined by DMA system and initial length of the measured spaceman.

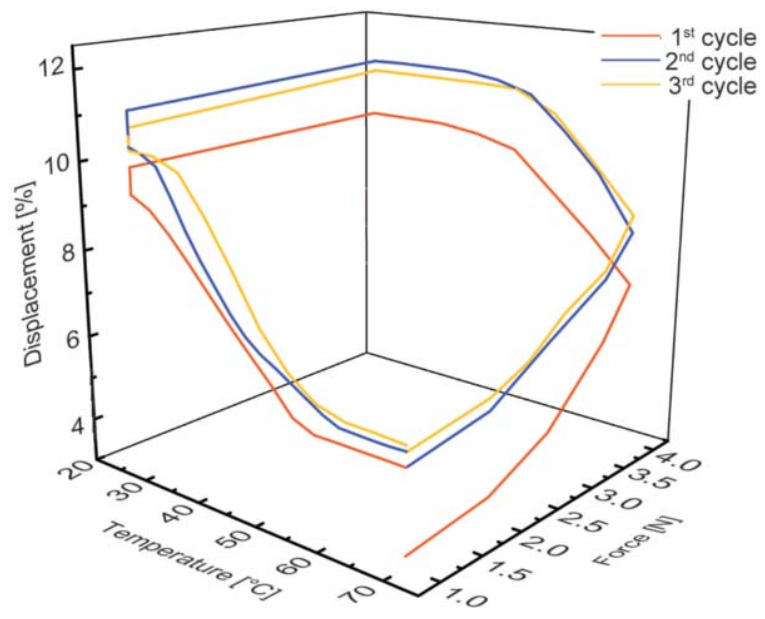

Figure 12. Shape memory thermo-mechanical cycles for RS-BOX:R-EP 50:50. 
cycle. The 3D chart (Figure 12) further verified our assumption since repeatable shape memory profiles of DMA cycle were achieved for all three cycles. In addition, the $R_{\mathrm{r}}$ values are in good agreement with recovery ratio values determined by the fold-deploy test (80-95\%; Figure 9), taking into consideration that recovery times at elevated temperature for DMA tests were approximately $10 \mathrm{~min}$. In the frame of established findings, higher recovery temperature and/or longer recovery time should improve the $R_{\mathrm{r}}$ straightforwardly.

The DMA cycle and fold-deploy test results, along with thermo-mechanical analysis, suggest that novel, fully bio-based resorcinol-based materials with shape memory ability can be tailored for related purposes by appropriately adapting starting ratio between epoxy and benzoxazine monomers. Different formulations allow adjusting the recovery time and its viscoelastic response/energy according to the application requirements. Furthermore, due to relatively wide glass transition windows, studied materials might possess multiple shape memory properties (mSMP). Among the new advanced materials, the mSMP polymers are suitable candidates for custom-made applications that require multi-step transitions. Consequently, such materials might be further adjusted to meet other objectives which should give the studied materials additional versatility as well as usability.

\section{Conclusions}

Fully bio-based benzoxazine-epoxy copolymers were successfully demonstrated to provide a one-way dual shape memory effect triggered by glass transition temperature. The curing of RS-BOX/R-EP reaction mixture consisted of overlapped peaks due to the presence of several reactions: the catalytic opening of oxazine ring and an epoxy group, the autocatalytic reaction of benzoxazine and etherification between benzoxazine and epoxide, and epoxy homopolymerization. The obtained SMPs showed excellent shape fixity values of about $97 \%$ and shape recovery up to $100 \%$ indicating good shape memory performance. The best combination of shape recovery time and mechanical properties was achieved by the equimolar ratio of RS-BOX and R-EP, where approximately 5 minutes were needed to recover its original shape at $T_{\mathrm{g}}+20^{\circ} \mathrm{C}$. In general, by increasing the ratio of RS-BOX in RS-BOX/R-EP copolymer the rise in the glass temperature was demonstrated. On the other hand, incorporation of R-EP in the RS-BOX matrix resulted in an increase of the width of the $\tan \delta$ peak, until an equimolar ratio was reached (50:50). The addition of bio-based benzoxazine resin as a co-curing agent for epoxy enables control over the shape fixity and recovery time. Furthermore, the prepared bio-based smart materials exhibit unique aptitude since final thermo-mechanical properties can be modified by solely changing the formulation of both starting monomers. Therefore, great versatility and flexibility in molecular design can be achieved, while studied materials might be used in a broader range of applications.

\section{Acknowledgements}

The authors acknowledge the financial support from the Slovenian Research Agency (research core funding No. P20191).

\section{References}

[1] Ratna D., Karger-Kocsis J.: Recent advances in shape memory polymers and composites: A review. Journal of Materials Science, 43, 254-269 (2008).

https://doi.org/10.1007/s10853-007-2176-7

[2] Liu Y., Du H., Liu L., Leng J.: Shape memory polymers and their composites in aerospace applications: A review. Smart Materials and Structures, 23, 023001/1023001/22 (2014).

https://doi.org/10.1088/0964-1726/23/2/023001

[3] Atli B., Gandhi F., Karst G.: Thermomechanical characterization of shape memory polymers. Journal of Intelligent Material Systems and Structures, 20, 87-95 (2009).

https://doi.org/10.1177/1045389X07086689

[4] Hu J., Zhu Y., Huang H., Lu J.: Recent advances in shape-memory polymers: Structure, mechanism, functionality, modeling and applications. Progress in Polymer Science, 37, 1720-1763 (2012).

https://doi.org/10.1016/J.progpolymsci.2012.06.001

[5] Karger-Kocsis J., Kéki S.: Biodegradable polyesterbased shape memory polymers: Concepts of (supra)molecular architecturing. Express Polymer Letters, 8, 397412 (2014).

https://doi.org/10.3144/expresspolymlett.2014.44

[6] Liu T., Hao C., Wang L., Li Y., Liu W., Xin J., Zhang J.: Eugenol-derived biobased epoxy: Shape memory, repairing, and recyclability. Macromolecules, 50, 85888597 (2017).

https://doi.org/10.1021/acs.macromol.7b01889

[7] Ma Z., Wang Y., Zhu J., Yu J., Hu Z.: Bio-based epoxy vitrimers: Reprocessibility, controllable shape memory, and degradability. Journal of Polymer Science Part A: Polymer Chemistry, 55, 1790-1799 (2017).

https://doi.org/10.1002/pola.28544 
[8] Li T., Liu X., Jiang Y., Ma S., Zhu J.: Bio-based shape memory epoxy resin synthesized from rosin acid. Iranian Polymer Journal, 25, 957-965 (2016). https://doi.org/10.1007/s13726-016-0482-0

[9] Liu L., Cai W.: Novel copolyester for a shape-memory biodegradable material in vivo. Materials Letters, 63, 1656-1658 (2009).

https://doi.org/10.1016/j.matlet.2009.04.037

[10] Zhang X., Tan B. H., Li Z.: Biodegradable polyester shape memory polymers: Recent advances in design, material properties and applications. Materials Science and Engineering: C, 92, 1061-1074 (2018). https://doi.org/10.1016/J.MSEC.2017.11.008

[11] Raidt T., Hoeher R., Meuris M., Katzenberg F., Tiller J. C.: Ionically cross-linked shape memory polypropylene. Macromolecules, 49, 6918-6927 (2016). https://doi.org/10.1021/acs.macromol.6b01387

[12] Arnebold A., Hartwig A.: Fast switchable, epoxy based shape-memory polymers with high strength and toughness. Polymer, 83, 40-49 (2016). https://doi.org/10.1016/j.polymer.2015.12.007

[13] Feldkamp D. M., Rousseau I. A.: Effect of the deformation temperature on the shape-memory behavior of epoxy networks. Macromolecular Materials and Engineering, 295, 726-734 (2010). https://doi.org/10.1002/mame.201000035

[14] Schäfer H., Hartwig A., Koschek K.: The nature of bonding matters: Benzoxazine based shape memory polymers. Polymer, 135, 285-294 (2018). https://doi.org/10.1016/j.polymer.2017.12.029

[15] Ivens J., Urbanus M., De Smet C.: Shape recovery in a thermoset shape memory polymer and its fabric-reinforced composites. Express Polymer Letters, 5, 254 261 (2011).

https://doi.org/10.3144/expresspolymlett.2011.25

[16] Rimdusit S., Kunopast P., Dueramae I.: Thermomechanical properties of arylamine-based benzoxazine resins alloyed with epoxy resin. Polymer Engineering and Science, 51, 1797-1807 (2011).

https://doi.org/10.1002/pen.21969

[17] Ishida H., Allen D. J.: Mechanical characterization of copolymers based on benzoxazine and epoxy. Polymer, 37, 4487-4495 (1996).

https://doi.org/10.1016/0032-3861(96)00303-5

[18] Wang Y-X., Ishida H.: Development of low-viscosity benzoxazine resins and their polymers. Journal of Applied Polymer Science, 86, 2953-2966 (2002).

https://doi.org/10.1002/app.11190

[19] Rimdusit S., Ishida H.: Development of new class of electronic packaging materials based on ternary systems of benzoxazine, epoxy, and phenolic resins. Polymer, 41, 7941-7949 (2000).

https://doi.org/10.1016/S0032-3861(00)00164-6

[20] Rimdusit S., Lohwerathama M., Hemvichian K., Kasemsiri P., Dueramae I.: Shape memory polymers from benzoxazine-modified epoxy. Smart Materials and Structures, 22, 075033/1-075033/12 (2013). https://doi.org/10.1088/0964-1726/22/7/075033
[21] Tanpitaksit T., Jubsilp C., Rimdusit S.: Effects of benzoxazine resin on property enhancement of shape memory epoxy: A dual function of benzoxazine resin as a curing agent and a stable network segment. Express Polymer Letters, 9, 824-837 (2015).

https://doi.org/10.3144/expresspolymlett.2015.77

[22] Likitaporn C., Mora P., Tiptipakorn S., Rimdusit S.: Recovery stress enhancement in shape memory composites from silicon carbide whisker-filled benzoxazineepoxy polymer alloy. Journal of Intelligent Material Systems and Structures, 29, 388-396 (2018). https://doi.org/10.1177/1045389X17708041

[23] Liu Y., Huang J., Su X., Han M., Li H., Run M., Song H., Wu Y.: Shape memory polybenzoxazines based on polyetheramine. Reactive and Functional Polymers, 102, 62-69 (2016). https://doi.org/10.1016/j.reactfunctpolym.2016.03.010

[24] Liu Y., Song S., Su X., Wang A., Shen S., Li C.: Effect of methyl position on the dynamic mechanical and shape-memory properties of cresol-based polybenzoxazines. Journal of Applied Polymer Science, 134, 45443/1-45443/8 (2017).

https://doi.org/10.1002/app.45443

[25] Prathumrat P., Tiptipakorn S., Rimdusit S.: Multipleshape memory polymers from benzoxazine-urethane copolymers. Smart Materials and Structures, 26, 065025/1-065025/9 (2017). https://doi.org/10.1088/1361-665x/aa6d47

[26] Dumas L., Bonnaud L., Olivier M., Poorteman M., Dubois P.: High performance bio-based benzoxazine networks from resorcinol and hydroquinone. European Polymer Journal, 75, 486-494 (2016). https://doi.org/10.1016/j.eurpolymj.2016.01.021

[27] Ambrožič R., Šebenik U., Krajnc M.: Synthesis, curing kinetics, thermal and mechanical behavior of novel cardanol-based benzoxazines. Polymer, 76, 203-212 (2015). https://doi.org/10.1016/j.polymer.2015.08.065

[28] Wang C., Sun J., Liu X., Sudo A., Endo T.: Synthesis and copolymerization of fully bio-based benzoxazines from guaiacol, furfurylamine and stearylamine. Green Chemistry, 14, 2799-2806 (2012).

https://doi.org/10.1039/c2gc35796h

[29] Chen Y-P., He X-Y., Dayo A. Q., Wang J-Y., Liu W-B., Wang J., Tang T.: Synthesis and characterization of cardanol containing tetra-functional fluorene-based benzoxazine resin having two different oxazine ring structures. Polymer, 179, 121620/1-121620/7 (2019). https://doi.org/10.1016/j.polymer.2019.121620

[30] Xu G-M., Shi T., Liu J., Wang Q.: Preparation of a liquid benzoxazine based on cardanol and the thermal stability of its graphene oxide composites. Journal of Applied Polymer Science, 131, 40353/1-40353/8 (2014). https://doi.org/10.1002/app.40353 
[31] Ambrožič R., Šebenik U., Krajnc M.: Epoxy emulsions stabilized with reactive bio-benzoxazine surfactant from epoxidized cardanol for coatings. European Polymer Journal, 81, 138-151 (2016).

https://doi.org/10.1016/j.eurpolymj.2016.05.029

[32] Arnebold A., Schorsch O., Stelten J., Hartwig A.: Resorcinol-based benzoxazine with low polymerization temperature. Journal of Polymer Science Part A: Polymer Chemistry, 52, 1693-1699 (2014).

https://doi.org/10.1002/pola.27169

[33] Schäfer H., Arnebold A., Stelten J., Marquet J., Sebastián R. M., Hartwig A., Koschek K.: Bifunctional benzoxazines: Synthesis and polymerization of resorcinol based single isomers. Journal of Polymer Science Part A: Polymer Chemistry, 54, 1243-1251 (2016).

https://doi.org/10.1002/pola.27966

[34] Dunkers J., Ishida H.: Vibrational assignments of 3alkyl-3,4-dihydro-6-methyl-2H-1,3-benzoxazines in the fingerprint region. Spectrochimica Acta Part A: Molecular and Biomolecular Spectroscopy, 51, 1061-1074 (1995). https://doi.org/10.1016/0584-8539(94)00114-Q

[35] Sawaryn C., Landfester K., Taden A.: Benzoxazine miniemulsions stabilized with polymerizable nonionic benzoxazine surfactants. Macromolecules, 43, 8933-8941 (2010). https://doi.org/10.1021/MA101169G

[36] Takeichi T., Guo Y., Rimdusit S.: Performance improvement of polybenzoxazine by alloying with polyimide: Effect of preparation method on the properties. Polymer, 46, 4909-4916 (2005). https://doi.org/10.1016/j.polymer.2005.03.096

[37] Wang J., Ren T-T., Wang Y-D., He X-Y., Liu W-B., Shen X-D.: Synthesis, curing behavior and thermal properties of fluorene-containing benzoxazines based on linear and branched butylamines. Reactive and Functional Polymers, 74, 22-30 (2014). https://doi.org/10.1016/j.reactfunctpolym.2013.10.008

[38] Rao B. S., Palanisamy A.: Synthesis of bio based low temperature curable liquid epoxy, benzoxazine monomer system from cardanol: Thermal and viscoelastic properties. European Polymer Journal, 49, 2365-2376 (2013). https://doi.org/10.1016/j.eurpolymj.2013.05.029

[39] Zhao S. F., Zhang G. P., Sun R., Wong C. P.: Curing kinetics, mechanism and chemorheological behavior of methanol etherified amino/novolac epoxy systems. Express Polymer Letters, 8, 95-106 (2014).

https://doi.org/10.3144/expresspolymlett.2014.12
[40] García-Garrido C., Sánchez-Jiménez P. E., PérezMaqueda L. A., Perejón A., Criado J. M.: Combined TGA-MS kinetic analysis of multistep processes. Thermal decomposition and ceramification of polysilazane and polysiloxane preceramic polymers. Physical Chemistry Chemical Physics, 18, 29348-29360 (2016).

https://doi.org/10.1039/c6cp03677e

[41] Ručigaj A., Alič B., Krajnc M., Šebenik U.: Curing of bisphenol A-aniline based benzoxazine using phenolic, amino and mercapto accelerators. Express Polymer Letters, 9, 647-657 (2015).

https://doi.org/10.3144/expresspolymlett.2015.60

[42] Jubsilp C., Punson K., Takeichi T., Rimdusit S.: Curing kinetics of benzoxazine-epoxy copolymer investigated by non-isothermal differential scanning calorimetry. Polymer Degradation and Stability, 95, 918-924 (2010). https://doi.org/10.1016/j.polymdegradstab.2010.03.029

[43] Chow W. S., Grishchuk S., Burkhart T., Karger-Kocsis J.: Gelling and curing behaviors of benzoxazine/epoxy formulations containing 4,4'-thiodiphenol accelerator. Thermochimica Acta, 543, 172-177 (2012). https://doi.org/10.1016/j.tca.2012.05.015

[44] Grishchuk S., Schmitt S., Vorster O. C., Karger-Kocsis J.: Structure and properties of amine-hardened epoxy/ benzoxazine hybrids: Effect of epoxy resin functionality. Journal of Applied Polymer Science, 124, 28242837 (2012). https://doi.org/10.1002/app.35302

[45] Ji F., Liu X., Lin C., Zhou Y., Dong L., Xu S., Sheng D., Yang Y.: Reprocessable and recyclable crosslinked polyethylene with triple shape memory effect. Macromolecular Materials and Engineering, 304, 1800528/11800528/8 (2019). https://doi.org/10.1002/mame.201800528

[46] Zhou S., Yang C., Hu J., He X., Zhang R.: Damping analysis of some inorganic particles on poly(butylmethacrylate). Materials, 11, 992/1-992/12 (2018). https://doi.org/10.3390/ma11060992

[47] Abdullah S. A., Jumahat A., Abdullah N. R., Frormann L.: Determination of shape fixity and shape recovery rate of carbon nanotube-filled shape memory polymer nanocomposites. Procedia Engineering, 41, 1641-1646 (2012). https://doi.org/10.1016/j.proeng.2012.07.362

[48] Kim B. K., Lee S. Y., Xu M.: Polyurethanes having shape memory effects. Polymer, 37, 5781-5793 (1996). https://doi.org/10.1016/S0032-3861(96)00442-9 